\title{
Dinamika Kelompok Peternak Sapi Potong Binaan Universitas Gadjah Mada di Propinsi Daerah Istimewa Yogyakarta
}

\author{
Siti Andarwati, Budi Guntoro, F. Trisakti Haryadi dan Endang Sulastri \\ Fakultas Peternakan Universitas Gadjah Mada, Jl. Fauna 3 Bulaksumur, Yogyakarta 55281 \\ Email: andar_siti@yahoo.com
}

\begin{abstract}
ABSTRAK
Penelitian ini bertujuan menganalisis tingkat kedinamisan kelompok peternak sapi potong binaan Universitas Gadjah Mada (Fakultas Peternakan) di Propinsi Daerah Istimewa Yogyakarta melalui unsur-unsur dinamika kelompok. Jumlah sampel adalah 77 peternak sapi potong anggota kelompok. Alat bantu yang digunakan adalah kuesioner yang telah teruji validitas dan reliabilitasnya. Penelitian menggunakan metode survey melalui tahapan persiapan dan pelaksanaan. Pada tahap persiapan dilakukan penentuan kelompok dan peternak sampel secara purposive random sampling. Hasil penelitian menunjukkan bahwa dinamika kelompok peternak sapi potong binaan Universitas Gadjah Mada di Propinsi Daerah Istimewa Yogyakarta termasuk dalam kategori tinggi. Dinamika kelompok yang paling tinggi adalah Kelompok Ngudi Barokah (Kulon Progo) yaitu sebesar 82,48\%, disusul oleh kelompok Sido Kumpul (Bantul) senilai 81,92\%, kemudian kelompok Bayu Andini (Sleman) senilai 77,22\%, dan terakhir kelompok Lembu Lestari (Gunungkidul) dengan nilai dinamika kelompoknya $73,02 \%$. Unsur-unsur pembentuk dinamika kelompok yaitu tujuan kelompok, struktur kelompok, fungsi tugas, pengembangan kelompok, kekompakan kelompok, suasana kelompok dan keefektifan kelompok memiliki nilai tinggi, sedangkan unsur tekanan kelompok memiliki nilai sedang.
\end{abstract}

Kata kunci: dinamika, kelompok, peternak, sapi potong

\section{Dynamics of Cattle Farmer Groups Assisted by Universitas Gadjah Mada in Yogyakarta Province}

\begin{abstract}
This study aimed to analyze the dynamics of cattle farmer groups assisted by Universitas Gadjah Mada (Faculty of Animal Science) in Yogyakarta Province. The total number of respondents were 77 farmers of cattle farmer groups. The tool used was a questionnaire that has proven validity and reliability. This study was conducted by survey method through the stages of preparation and execution. In the preparation phase carried out the determination of groups and cattle farmer samples using pusposive random sampling. The results showed that the dynamics of cattle farmer groups assisted by Universitas Gadjah Mada in Yogyakarta Province included in the high category. The highest group dynamics was Ngudi Barokah Group in Kulonprogo (equal to 82.48\%), followed by the Sido Kumpul Group in Bantul (81.92\%), then Bayu Andini Group in Sleman (77.22\%), and Lembu Lestari Group in Gunungkidul (73.02\%). Constituent elements of the group dynamics of goals, group structure, function assignments, development, cohesiveness, atmosphere and effectiveness of the group had a high level, while the group pressure was ini medium level.
\end{abstract}

Key words: dynamics, group, farmer, cattle 


\section{PENDAHULUAN}

Pembangunan peternakan memerlukan peningkatan kualitas manusia agar dapat memanfaatkan sumberdaya alam untuk kepentingan manusia itu sendiri. Peningkatan kualitas manusia memerlukan penyampaian teknologi kepada masyarakat terutama petani di pedesaan. Para petani dan peternak memperoleh pengetahuan, ketrampilan dan sikap tentang suatu teknologi dari pengalaman mereka seharihari. Keadaan ini tentunya memerlukan waktu yang lama, sedangkan peningkatan produksi merupakan kebutuhan yang sangat mendesak. Salah satu cara yang dapat digunakan untuk menyampaikan teknologi kepada masyarakat peternak agar efektif adalah melalui pemanfaatan kelompok peternak.

Kelompok menurut Santosa (1999) adalah suatu unit yang terdapat beberapa individu, yang mempunyai kemampuan untuk berbuat dengan kesatuannya dengan cara dan atas dasar kesatuan persepsi. Kelompok mempunyai keragaman dalam banyak hal, yakni ukuran, lamanya, nilainilai dari tujuan, ruang lingkup dan yang terpenting adalah keragaman dalam ukuran kelompok. Kelompok kecil memiliki anggota tiga sampai 20 orang dan apabila lebih disebut sebagai organisasi formal (Sears dkk, 1999).

Mardikanto (1993) mengatakan bahwa ciri-ciri utama kelompok yaitu memiliki ikatan yang nyata, interaksi dan interrelasi sesama anggotanya, struktur dan pembagian tugas yang jelas, kaidah-kaidah atau normanorma tertentu yang disepakati bersama dan keinginan dan tujuan bersama. Menurut Cartwright dan Zander (1986), sekuangkurangnya ada tiga kondisi yang memungkinkan pembentukan suatu kelompok, yaitu: a) Kelompok yang dibentuk oleh satu orang atau lebih dengan maksud-maksud tertentu; b) Suatu kelompok yang dibentuk secara spontan; c) Sekumpulan individu menjadi suatu kelompok karena diperlakukan yang sama oleh orang lain.
Kelompok memiliki banyak jenis atau tipe, salah satunya adalah kelompok tani. Kelompok tani adalah sejumlah petani yang mempunyai hubungan antara satu dengan yang lainnya. Hubungan tersebut timbul atas dasar kebutuhan sama yang terikat dalam satu hubungan intern yang cukup stabil, serasi dan tercapai. Hubungan yang ada didasari satu minat yang sama dalam rangka menjamin kelangsungan hidup dari kelompok itu serta memungkinkan pelaksanaan usaha taninya, dengan menitikberatkan kegiatan-kegiatan kerjasama dalam usaha menanggulangi masalah peningkatan produksi (Guntoro dan Sulastri, 1998).

Fuad (1996) mengatakan bahwa, suatu kelompok yang berkembang jika ada upaya perbaikan dan penyempurnaan yang terus menerus dilakukan sehingga suatu kelompok cenderung berubah dari satu pola ke pola lainnya sesuai corak dan kepesatan perubahan itu sendiri.

Studi tentang kehidupan kelompok sangat diperlukan untuk dapat membantu usaha pemanfaatan kelompok dalam bidang peternakan. Permasalahan yang dihadapi adalah sulitnya mendapatkan kelompok peternak yang dinamis sehingga dapat menunjang pembangunan bidang peternakan. Dalam menilai kedinamisan kelompok perlu mengeksplorasi segala kekuatan yang ada di dalam kelompok yang dapat menentukan perilaku kelompok dan perilaku anggota kelompok untuk tercapainya tujuan kelompok. Berdasarkan unsur-unsur kekuatan tersebut diharapkan dapat diketahui faktor apa saja yang harus diciptakan, terutama yang ada dalam kelompok itu sendiri, sehingga kedinamisan suatu kelompok dapat terwujud yang pada akhirnya pemanfaatan kelompok dapat dilakukan secara optimal. Kekuatankekuatan di dalam kelompok yang menentukan perilaku kelompok dan anggota kelompok itulah yang disebut dengan dinamika kelompok.

Johnson dan Johnson (1991) menyatakan bahwa dinamika kelompok adalah suatu ilmu yang mempelajari tingkah 
laku kelompok untuk kemajuan pengetahuan tentang sifat kelompok, perkembangan kelompok, interaksi di antara kelompok dan individu, antara kelompok dengan kelompok lain, sedangkan dinamika kelompok menurut Padmanegara (1996) merupakan sasaran atau penekanan dalam pendidikan petani cara petani belajar dari pengalaman, usaha menemukan sendiri dan kerjasama antar petani.

Keberhasilan suatu kelompok pada hakikatnya menurut Mardikanto (1993), terletak pada dinamika kelompok. Dinamika kelompok merupakan kekuatan-kekuatan yang muncul dari dalam kelompok yang dicirikan oleh sembilan unsur yakni: (1) tujuan kelompok, (2) struktur kelompok, (3) fungsi tugas kelompok, (4) pengembangan kelompok, (5) kekompakan kelompok, (6) suasana kelompok, (7) tekanan kelompok dan (8) keefektifan kelompok. Unsur-unsur tersebut menyebabkan kelompok hidup, bergerak, aktif dan produktif dalam mencapai tujuan. Dinamika kelompok digerakkan oleh sikap kelompok. Sikap kelompok terlihat dari sikap individuindividu anggotanya. Suatu kelompok dikatakan dinamis jika interaksi sesama anggota lebih kuat dibanding interaksi dengan pihak luar kelompoknya. Makin kuat interaksi diantara peternak anggota, makin kompak kelompok tersebut dan makin mudah dalam mencapai tujuan.

Daerah Istimewa Yogyakarta (DIY) merupakan salah satu propinsi pendukung utama $(1,88 \%)$ untuk populasi sapi potong di Pulau Jawa (45,52\% populasi sapi potong di Indonesia). Pengembangan potensi peternakan sapi potong di Propinsi Daerah Istimewa Yogyakata sebagai bagian integral dari pembangunan pertanian, juga dilakukan dengan membentuk kelompok peternak sapi potong. Pembentukan kelompok peternak sapi potong tersebut ditindaklanjuti dengan usaha membentuk suatu sistem perkampungan ternak sapi potong. Kabupaten Sleman merupakan perintis pembentukan kelompok peternak dengan sistem tersebut diikuti Kabupaten Bantul, Kulon Progo, dan Gunungkidul.
Berdasarkan landasan teori tersebut, maka penelitian ini akan mendapatkan keterangan empiris tingkat dinamika kelompok peternak sapi potong di Propinsi DIY mencakup Kabupaten Sleman, Kulon Progo, Bantul dan Gunungkidul.

\section{MATERI DAN METODE}

Materi penelitian adalah kelompok peternak sapi potong yang ada di Kabupaten Sleman, Kulon Progo, Bantul dan Gunungkidul. Jumlah kelompok yang dijadikan sampel adalah 1 kelompok binaan Fakultas Peternakan UGM untuk setiap kabupaten, sedangkan jumlah peternak anggota kelompok yang dijadikan sampel berjumlah maksimal 20 peternak untuk setiap kelompok yang memiliki lebih dari 20 anggota, sedangkan yang memiliki kurang dari 20 anggota diambil seluruhnya. Jumlah seluruh kelompok sampel adalah 4 kelompok binaan peternak sapi potong dengan jumlah peternak sampel adalah 77 peternak sapi potong anggota kelompok, masing-masing dari Kelompok Sido Kumpul (Bantul) 20 responden, Kelompok Lembu Lestari (Gunungkidul) 17 responden, Kelompok Ngudi Barokah (Kulon Progo) 20 responden dan Kelompok Bayu Andini (Sleman) 20 responden. Alat bantu yang digunakan adalah kuesioner yang telah teruji validitas dan reliabilitasnya.

Penelitian ini menggunakan metode survey melalui tahapan persiapan dan pelaksanaan. Pada tahap persiapan dilakukan penentuan kelompok dan peternak sampel. Penentuan kelompok dilakukan secara purposive random sampling. Syarat kelompok yang dapat dijadikan sampel adalah kelompok tersebut masih aktif terutama dalam aktivitas kelompok dan usaha peternakan sapi potong. Penentuan sampel peternak juga dilakukan secara purposive random sampling yakni maksimal 20 peternak perkelompok dengan ketentuan masih aktif dalam kegiatan kelompok dan berusaha ternak sapi potong.

Indikator variabel dinamika kelompok adalah unsur-unsur dinamika kelompok yang 
terdiri dari sembilan unsur yakni (1) tujuan kelompok, (2) struktur kelompok, (3) fungsi tugas kelompok, (4) pengembangan kelompok, (5) kekompakan kelompok, (6) suasana kelompok, (7) tekanan kelompok dan (8) keefektifan kelompok. Masingmasing indikator variabel dinamika kelompok dijabarkan secara detail melalui item-item pernyataan.

Skala pengukuran indikator variabel dinamika kelompok menggunakan sistem penskalaan subyek dengan memberikan skor sesuai dengan nilai skala yang telah diberi bobot pada kategori jawaban yang diberikan. Skor yang digunakan mempunyai rentangan yang bergerak dari skor 1 (rendah), sampai dengan 4 (tinggi). Berdasarkan persentase yang dapat dicapai oleh masing-masing unsur dinamika kelompok dan keseluruhan unsur dinamika kelompok, maka tingkat dinamika kelompok peternak sapi potong di masing-masing kabupaten dikategorikan rendah $(\leq 33,3 \%)$, sedang $(33,4 \%-66,6 \%)$ dan tinggi $(66,7 \%$ - 100\%). Selanjutnya analisis deskriptif digunakan untuk menggambarkan tingkat dinamika kelompok.

\section{HASIL DAN PEMBAHASAN}

\section{Karakteristik Kelompok}

\section{Kelompok Sido Kumpul}

Kelompok peternak Sido Kumpul berlokasi di Dusun Kragilan, Desa Tamanan Kecamatan Banguntapan, Kabupaten Bantul. Kelompok ini berdiri tahun 1995 (usia kelompok 15 tahun). Pada saat kelompok ini didirikan, jumlah anggota peternak ada 11 orang, namun setelah mengalami perkembangan, saat ini jumlah anggota sebanyak 43 peternak. Jumlah sapi saat berdiri sejumlah 20 ekor dan saat ini berjumlah 109 (Jantan: 51, Betina : 46, Pedet jantan : 12). Jenis sapi yang dipelihara : PO, Simpo dan Limpo. Tujuan Kelompok adalah meningkatkan kebersihan lingkungan, meningkatkan pendapatan peternak sekitar dan memberikan tempat bagi peternak. Tujuan anggota (responden) beternak dalam kelompok adalah meningkatkan pendapatan.

\section{Kelompok Bayu Andini}

Kelompok ini berlokasi di Dusun Kalongan, Desa Tlogoadi, Kecamatan Mlati, Kabupaten Sleman. Kelompok ini berdiri tahun 1992 (usia kelompok 18 tahun). Jumlah anggota saat kelompok didirikan adalah 19 peternak dengan kepemilikan sapi sebanyak 38 ekor. Saat ini jumlah anggota mencapai 26 orang dengan kepemilikan sapi sebanyak 63 ekor (Jantan : 9, Betina : 32, Calon pejantan : 4, Dara : 8, Pedet jantan : 3 , Pedet betina : 10). Jenis sapi yang dipelihara : PO dan Limpo. Tujuan Kelompok adalah meningkatkan kebersihan lingkungan dusun, meningkatkan kesejahteraan anggota dan memudahkan pengawasan, sedangkan tujuan anggota (responden) beternak dalam kelompok adalah menambah penghasilan.

\section{Kelompok Ngudi Barokah}

Kelompok Ngudi Barokah di Dukuh V, Desa Bojong, Kecamatan Panjatan, Kabupaten Kulon Progo. Kelompok ini didirikan pada tahun 2008 (usia kelompok baru mencapai 2 tahun). Jumlah anggota saat berdiri sebanyak 15 orang, namun dalam kurun dua tahun jumlah anggota bertambah dengan jumlah total saat ini sebanyak 25 anggota. Penambahan jumlah sapi pun bertambah, dari 25 ekor, menjadi 37 ekor (Jantan : 8, Betina : 12, Calon pejantan : 0, Dara : 10, Pedet jantan : 2, Pedet betina : 5). Jenis sapi yang dipelihara : PO, Simpo dan Limpo. Tujuan Kelompok adalah meningkatkan kesejahteraan penduduk sekitar, sedangkan tujuan anggota (responden) beternak dalam kelompok meningkatkan pendapatan dan mencari pengalaman.

\section{Kelompok Lembu Lestari}

Kelompok ini berdiri tahun 2003 (usia kelompok 7 tahun), berlokasi di Dusun Tompak, Desa Ngawu, Kecamatan Playen, Kabupaten Gunungkidul. Jumlah anggota saat berdiri sejumlah 25 orang dengan kepemilikan sapi sejumlah 40 ekor. Saat ini 
jumlah anggota 18 orang, dengan kepemilikan sapi sebanyak 42 ekor (Jantan : 2, Betina : 23, Dara : 1, Pedet jantan : 6 Pedet betina : 10). Jenis sapi yang dipelihara : PO, Simpo dan Limpo. Tujuan Kelompok adalah turut serta memajukan peternakan Indonesia dan meningkatkan pendapatan peternak sekitar. Tujuan anggota (responden) beternak dalam kelompok adalah menabung untuk keluarga.

\section{Dinamika Kelompok Peternak}

Dinamika kelompok dapat dilihat melalui unsur-unsur pembentuknya, yaitu tujuan kelompok, struktur kelompok, fungsi tugas, pengembangan kelompok, kekompakan kelompok, suasana kelompok, tekanan kelompok dan keefektifan kelompok. Tabel 1 menyajikan ringkasan nilai dinamika kelompok berdasarkan unsurunsurnya dan kelompok peternak.

Berdasarkan Tabel 1, rata-rata nilai dinamika kelompok di keempat kelompok peternak sapi adalah $78,66 \%$, yang dapat dikategorikan memiliki dinamika kelompok yang tinggi. Untuk masing-masing kelompok, dinamika kelompok yang paling tinggi adalah Kelompok Ngudi Barokah (Kulon Progo) yaitu sebesar 82,48\%, disusul oleh kelompok Sido Kumpul (Bantul) senilai 81,92\%, kemudian kelompok Bayu Andini (Sleman) senilai $77,22 \%$, dan terakhir kelompok Lembu Lestari (Gunungkidul) dengan nilai dinamika kelompoknya $73,02 \%$. Berikut adalah penjelasan masingmasing unsur dinamika kelompok pada keempat kelompok.

\section{Tujuan kelompok}

Tujuan kelompok merupakan hasil akhir yang ingin dicapai, baik berupa suatu obyek atau keadaan serta keinginankeinginan lain yang diinginkan dan dapat memuaskan semua anggota kelompok yang bersangkutan (Krech, 1962 yang disitasi oleh Mardikanto, 1993). Adanya tujuan kelompok akan menggerakkan semua anggota untuk berperilaku atau melaksanakan kegiatan demi tercapainya tujuan yang diinginkan. Karena itu, harus diupayakan secara sederhana tetapi jelas agar setiap anggota memahami tujuan kelompoknya. Kejelasan tujuan kelompok akan sangat berpengaruh terhadap perilaku atau tindakan anggota kelompok sehingga perlu dikaji sampai sejauh mana tujuan kelompok benar-benar telah dipahami dan dihayati oleh setiap anggota kelompok yang bersangkutan.

Tujuan kelompok terdiri dari dua kategori yaitu kejelasan tujuan kelompok dan kesesuaian kelompok dengan tujuan anggota. Berdasarkan Tabel 1, nilai yang didapat untuk setiap kelompoknya adalah yang tertinggi Ngudi Barokah, disusul kelompok Sido Kumpul, Bayu Andini, dan Lembu Lestari, dengan nilai sebesar 88,75\%, $88,13 \%, 81,25 \%$ dan $75,00 \%$, sehingga dapat dikatakan semua kelompok memiliki nilai dinamika kelompok dengan unsur tujuan kelompok adalah kategori tinggi. Hal ini menunjukkan bahwa sebagian besar harapan peternak benar-benar jelas terhadap tujuan kelompok dan tujuan kelompok tersebut sesuai dengan tujuan yang diharapkan peternak secara individual. Nilai tertinggi ada pada kelompok Ngudi Barokah (Kulon Progo), keadaan tersebut dapat dimaklumi bahwa usia kelompok tersebut masih sangat muda (baru dua tahun) sehingga masih memiliki motivasi yang kuat dalam berkelompok berdasarkan kesepakatan bersama.

Pemahaman yang jelas dengan tujuan kelompok berarti mereka tahu, mampu menyebutkan tujuan kelompoknya dan menyatakan bahwa tujuan kelompok tersebut sesuai dengan keinginan secara pribadi peternak anggota. Anggota kelompok akan turut serta ambil bagian dalam kegiatan bersama dalam kelompok apabila tujuannya memang sesuai dengan tujuan pribadi dan kegiatannya menurut mereka baik dan bermanfaat. Mardikanto (1993) menyatakan bahwa kejelasan tujuan kelompok akan sangat berpengaruh terhadap perilaku atau tindakan anggota kelompok, sebab kejelasan tujuan akan memotivasi angota untuk terus berusaha mencapai 
Tabel 1. Hasil perhitungan tingkat dinamika kelompok

\begin{tabular}{|c|c|c|c|c|c|}
\hline \multirow[b]{2}{*}{ Unsur dinamika kelompok } & \multicolumn{5}{|c|}{ Nilai (\%) } \\
\hline & $\begin{array}{l}\text { Sido Kumpul } \\
\text { (Bantul) }\end{array}$ & $\begin{array}{c}\text { Lembu } \\
\text { Lestari } \\
\text { (Gunung } \\
\text { kidul) }\end{array}$ & $\begin{array}{c}\text { Ngudi } \\
\text { Barokah } \\
\text { (Kulon } \\
\text { Progo) }\end{array}$ & $\begin{array}{c}\text { Bayu } \\
\text { Andini } \\
\text { (Sleman) }\end{array}$ & $\begin{array}{l}\text { Rata- } \\
\text { rata }\end{array}$ \\
\hline Tujuan kelompok & 88,13 & 75,00 & 88,75 & 81,25 & 83,28 \\
\hline Struktur kelompok & 90,63 & 75,74 & 86,04 & 90,42 & 85,71 \\
\hline Fungsi tugas & 83,44 & 76,10 & 85,42 & 80,63 & 81,40 \\
\hline Pengembangan kelompok & 79,69 & 60,91 & 78,54 & 70,63 & 72,44 \\
\hline Kekompakan kelompok & 84,50 & 77,06 & 85,25 & 84,25 & 82,77 \\
\hline Suasana kelompok & 100,00 & 100,00 & 95,63 & 90,63 & 96,56 \\
\hline Tekanan kelompok & 48,13 & 48,28 & 62,29 & 40,83 & 49,88 \\
\hline Keefektifan kelompok & 80,83 & 71,08 & 77,92 & 79,17 & 77,25 \\
\hline Nilai Dinamika kelompok & 81,92 & 73,02 & 82,48 & 77,22 & 78,66 \\
\hline
\end{tabular}

Sumber : Data primer terolah (2010)

tujuan. Apabila anggota kelompok tidak mengetahui tujuan kelompoknya, maka selama ikut dalam kelompok mereka tidak tahu arah tujuan kelompok dan berakibat kelompok menjadi pasif dan tidak produktif.

Hasil penelitian sejalan dengan pendapat Santosa (1999), yang menyatakan bahwa kesatuan persepsi para anggota termasuk dalam pemahaman tujuan kelompok, akan berpengaruh pada kemajuan kelompok tersebut. Kejelasan tujuan kelompok dan kesesuaian tujuan kelompok dengan tujuan anggota akan mengikat seluruh anggota kelompok menjadi satu kesatuan dan akan menyebabkan kelompok menjadi dinamis dan fungsional.

\section{Struktur kelompok}

Struktur kelompok adalah suatu pola yang teratur tentang bentuk tata hubungan antara individu-individu kelompok yang sekaligus menggabarkan kedudukan dan peran masing-masing dalam upaya pencapaian kelompok. Ketidakjelasan mengenai struktur kelompok akan berpengaruh terhadap ketidakjelasan kedudukan, peran, hak, kewajiban dan kekuasaan masing-masing anggota, sehingga pelaksanaan kegiatan tidak mungkin dapat berlangsung secara efektif dan efisien untuk mencapai tujuan kelompok. Pada unsur ini terdapat tiga kategori pengukuran yaitu struktur kekuasaan/pengambilan keputusan, struktur tugas/pembagian tugas dan struktur komunikasi.

Berdasarkan Tabel 1. Rata-rata nilai dari keempat kelompok yang diteliti untuk nilai dinamika kelompok unsur struktur kelompok adalah kategori tinggi yaitu senilai 85,71\%. Kelompok Sido Kumpul dan Bayu Andini memiliki persentase yang sangat tinggi yaitu masing-masing senilai 90,63\% dan 90,42\%, sedangkan Kelompok Ngudi Barokah dan Lembu Lestari masingmasing $86,04 \%$ dan $75,74 \%$. Namun demikian keempat kelompok tersebut digolongkan ke dalam dinamika kelompok unsur struktur kelompok kategori tinggi.

\section{Fungsi Tugas}

Fungsi tugas adalah hal-hal apa saja yang dilakukan kelompok dalam menjalankan fungsinya. Keenam kategori yang merupakan pengukur fungsi tugas tersebut adalah: 1) fungsi penyebaran informasi, 2) fungsi memuaskan anggota, 3) fungsi penyelenggaraan koordinasi, 4) fungsi penumbuhan inisiatif, 5) fungsi mengajak berpartisipasi dan 6) fungsi menjelaskan. Fungsi tugas merupakan seperangkat tugas yang harus dilakukan oleh setiap anggota suatu kelompok sesuai dengan fungsi masing-masing serta kedudukannya dalam struktur kelompok.

Berdasarkan Tabel 1, dapat dijelaskan bahwa rata-rata nilai fungsi tugas dari 
keempat kelompok yang diteliti adalah dalam kategori yang tinggi yaitu sebesar $81,40 \%$. Nilai tertinggi terdapat pada kelompok Ngudi Barokah (Kulon Progo) yaitu 85,42\%, kemudian diikuti oleh kelompok Sido Kumpul, Bayu Andini dan Lembu Lestari, masing-masing sebesar $83,44 \%, 80,63 \%$ dan $76,10 \%$.

Sebagian besar anggota merasa mudah dalam mendapatkan informasi. Keadaan ini merupakan salah satu keuntungan dari dibentuknya kelompok peternak. Meskipun informasi yang didapatkan anggota mudah diperoleh lewat pertemuan kelompok tetapi informasi tersebut kadang dirasakan oleh anggota kurang sesuai dengan kebutuhan anggota.

\section{Pengembangan Kelompok}

Pengembangan kelompok peternak ini diukur dari partisipasi anggota kelompok, pengembangan fasilitas kelompok, menumbuhkan kegiatan kelompok, kontrol sosial/pengawasan, proses sosialisasi dan mendapatkan anggota baru. Rata-rata nilai fungsi pengembangan kelompok adalah $72,44 \%$ dan masih dalam kategori nilai yang tinggi. Kelompok Sido Kumpul memiliki nilai yang tertingi di antara keempat kelompok yang diteliti yaitu sebesar 79,96\%, yang kemudian diikuti oleh kelompok Ngudi Barokah, Bayu Andini, dan Lembu Lestari, masing-masing 78,54\%, $70,63 \%$ dan $60,91 \%$. Nilai yang diperoleh kelompok Lembu Lestari dalam kategori sedang $(60,91 \%)$. Hal ini dapat dijelaskan bahwa dalam kurun waktu 7 tahun (sejak berdiri tahun 2003) terdapat penyusutan jumlah anggota kelompok yaitu dari 25 menjadi 18 anggota, walaupun jumlah ternak rata-rata naik peranggota. Dari total berjumlah 42 ekor untuk 25 orang, menjai 42 ekor dari 18 anggota. Penyebab dari menurunnya jumlah anggota kelompok ini adalah kurang adanya ikatan antara pengurus dengan anggota, sehingga banyak anggota kelompok yang merasa sedikit menerima manfaat dari keikutsertaannya di dalam kelompok. Letak geografis juga menentukan pengembangan kelompok dari Gunungkidul ini. Hal ini berlainan dengan kondisi geografis dari ketiga kelompok lainnya. Jarak antara satu anggota dengan anggota lainnya relatif berjauhan, sehingga diperlukan upaya keras dalam pengembangan kelompok di daerah ini.

\section{Kekompakan kelompok}

Kekompakan kelompok merupakan keterkaitan anggota kelompok terhadap kelompoknya, baik secara fisik maupun emosional dalam upaya melaksanakan dan mencapai tujuan kelompok. Rasa keterkaitan ini dapat ditunjukkan pada kesamaan tindakan, kerjasama, persamaan nasib, homogenitas perilaku, kesadaran menjadi anggota, kesepakatan terhadap tujuan kelompok, dan pengakuan terhadap kepemimpinan kelompok. Unsur kekompakan dalam penelitian ini diukur dari 1) penilaian anggota terhadap pemimpin kelompok, 2) keanggotaan kelompok 3) nilai tujuan kelompok, 4) keterpaduan kegiatan kelompok dan 5) jiwa kerjasama.

Hasil penelitian menunjukkan bahwa rata-rata nilai unsur kekompakan dari keempat kelompok yang diteliti adalah $82,77 \%$ yang digolongkan dalam kategori tinggi. Masing-masing nilai dari keempat kelompok adalah Ngudi Barokah (85,25\%), Sido Kumpul (84,50\%), Bayu Andini (84,25\%) dan Lembu Lestari (77,06\%).

\section{Suasana Kelompok}

Suasana kelompok tani merupakan lingkungan fisik dan anggota non fisik yang akan mempengaruhi perasaan setiap anggota terhadap kelompoknya. Suasana tersebut berupa keramahtamahan, kesetiakawanan, kebebasan bertindak dan suasana fisik. Tabel 1 menunjukkan bahwa rata-rata unsur suasana kelompok pada keempat kelompok adalah tinggi $(96,56 \%)$. Nilai sempurna (100\%) terdapat pada kelompok Sido Kumpul di Bantul dan kelompok Lembu Lestari di Gunungkidul, sedangkan kelompok lainnya yaitu Ngudi barokah dan Bayu Andini masing-masing 95,63 dan $90,63 \%$ yang masih dalam skala tinggi. Hubungan antar anggota dinilai baik, artinya 
di antara anggota saling rukun dan akrab. Hubungan yang baik ini dapat tumbuh oleh tiga sikap, yaitu kepercayaan, sikap yang saling mendukung dan sikap terbuka.

\section{Tekanan Kelompok}

Tekanan kelompok yaitu tekanan dalam kelompok yang menyebabkan kelompok tersebut berusaha keras untuk mencapai tujuan kelompok, yaitu persaingan untuk maju, penghargaan terhadap anggota, sanksi dan hukuman. Bedasarkan Tabel 1. Ngudi Barokah merupakan kelompok yang memiliki dinamika pada unsur tekanan kelompok yang paling tinggi di antara keempat kelompok, yaitu $62,29 \%$ yang masuk dalam skala sedang, sedangkan kelompok Sido Kumpul, Lembu Lestari, dan Bayu Andini, masing-masing memiliki nilai $48,13 \%$, 48,28\%, dan $40,83 \%$, dan dalam tingkat dinamika yang sedang.

\section{Keefektifan Kelompok}

Keefektifan kelompok yaitu keberhasilan kelompok untuk mencapai tujuannya, yang dapat dilihat pada tercapainya keadaan atau perubahanperubahan yang memuaskan anggotanya. Dari hasil penelitian, kelompok Sido Kumpul memiliki keefektifan yang paling tinggi yaitu $80,83 \%$, diikuti Bayu Andini 79,17\%, Ngudi Barokah 77,92\% dan Lembu Lestari $71,08 \%$ dan semua kelompok tersebut dalam kategori tinggi. Tingginya nilai keefektifan kelompok ini ditunjukkan oleh tercapainya tujuan kelompok, rasa kebanggaan anggota terhadap kelompoknya, serta rasa puasnya anggota terhadap tujuan yang telah dicapai.

\section{KESIMPULAN}

Dinamika kelompok peternak sapi potong binaan Universitas Gadjah Mada (Fakultas Peternakan) di Propinsi Daerah Istimewa Yogyakarta termasuk dalam kategori tinggi. Dinamika kelompok yang paling tinggi adalah Kelompok Ngudi Barokah (Kulon Progo) yaitu sebesar $82,48 \%$, disusul oleh kelompok Sido
Kumpul (Bantul) senilai 81,92\%, kemudian kelompok Bayu Andini (Sleman) senilai $77,22 \%$, dan terakhir kelompok Lembu Lestari (Gunungkidul) dengan nilai dinamika kelompoknya $73,02 \%$.

Unsur-unsur pembentuk dinamika kelompok yaitu tujuan kelompok, struktur kelompok, fungsi tugas, pengembangan kelompok, kekompakan kelompok, suasana kelompok dan keefektifan kelompok memiliki nilai tinggi, sedangkan unsur tekanan kelompok memiliki nilai sedang.

Pembinaan pada kelompok peternak sapi potong yang merupakan binaan Fakultas Peternakan UGM perlu memberikan penekanan pada aspek untuk peningkatan tekanan kelompok sehingga dinamika kelompok dapat ditingkatkan. Aspek persaingan untuk maju harus terus dimotivasi, penghargaan untuk anggota perlu diberikan dan ditingkatkan, begitu pula dengan adanya sanksi dan hukuman yang tegas dan jelas wajib diberlakukan sehingga kelompok dapat berjalan dengan baik.

\section{DAFTAR PUSTAKA}

Cartwright, D. And A. Zander. 1968. Group Dynamics. Pelajar, Yogyakarta.

Fuad, M. 1996. Menjawab Dinamika Tuntutan Permintaan Pasar. Ekstensia Volume III tahun II. Pusat Penyuluhan Pertanian.

Guntoro, B, dan E. Sulastri. 1998. Dinamika kelompok tani-ternak Sapi Potong Sistem Kandang Kelompok di Kabupaten Bantul. Fakultas Peternakan UGM, Yogyakarta.

Johnson, D. W. and F. P. Johnson. 1991. Joining Together: Group Theory and Group

Skills. Forth Edition, Prentice-Hall International Inc. New Jersey.

Mardikanto, T. 1993. Penyuluhan Pembangunan Pertanian. UNS Press, Surakarta.

Padmanegara, S. 1996. Pendidikan Pertanian untuk Petani. Ekstensia Volume II Tahun II, Pusat Penyuluhan Pertanian, Jakarta.

Santosa, S. 1999. Dinamika Kelompok. Bumi Aksara. Surabaya.

Sears, O.D. , J.L. Freedman, and L.A. Peplas. 1999. Psikologi Sosial. Edisi V. Jilid 2. Erlangga, Jakarta. 